\title{
Clinical training experience in district general hospitals
}

\author{
Roderick MacFaul, Stephen Jones, Ursula Werneke
}

\begin{abstract}
Aims-To estimate the nature and quantity of clinical experience available for trainees in paediatrics or general practice in acute general hospitals of differing sizes in the UK. To discuss implications for training and service configuration taking account of current Royal College recommendations (a minimum of 1800 acute contacts each year and ideally covering a population of 450000 to 500000 people).
\end{abstract}

Methods-Observed frequencies of diagnoses in Pinderfields Hospital, Wakefield hospitals in Yorkshire and four in the South of England, and with expected frequencies from a review of selected marker conditions using national routine and epidemiological data. Based on the Pinderfields data, we modelled expected frequencies of a wider range of diagnoses for different sized hospitals.

Results-Small units (1800 or less acute referrals a year) provide adequate exposure to common conditions such as gastroenteritis (157 per annum) and asthma (171 per annum) but encounter serious or unusual disease rarely. When modelled for units serving larger populations, numbers of such disorders remain small. For example, about $0.5 \%$ of admissions require intensive care to the level of ventilatory support. Medium size units offer a wide range of experience but differ little from those serving the population of 500000 proposed as being optimal for training. This standard is not justified by the evidence in this review. Closing or amalgamating units on the scale necessary to achieve this ideal would be impractical as only five hospitals in England have a paediatric workload equivalent to this population; it would also raise issues of access and equity.

(Arch Dis Child 2000;83:39-44)

Paediatric

Pinderfields Hospital,

Pinderfields and

Pontefract NHS Trust,

Wakefield WF14 DG,

UK

R MacFaul

S Jones

Maudsley Hospital,

Denmark Hill, London

SE5 8AZ, UK

U Werneke

Correspondence to:

Dr MacFaul

email:mfrod@easynet.co.uk

Accepted 20 March 2000

In its guidance document, Future configuration of paediatric units, the British Paediatric Association (BPA), now Royal College of Paediatrics and Child Health (RCPCH), advised that smaller paediatric units should amalgamate whenever possible to provide sufficient training experience and reinforcement of expertise. ${ }^{1}$ This was based on the premise that a small unit, arbitrarily defined as one dealing with 1800 acute paediatric contacts per year, does not offer sufficient experience to provide were compared with those in five other

adequate training for doctors aiming either for general practice (family practice) or paediatrics. But evidence to support this standard is limited. We have reviewed available data to provide information on which judgements may be made. Using extrapolation from recent studies, we estimated the quantity and nature of clinical experience that is likely to be offered to a trainee in paediatrics or general practice over one year in acute general hospitals of differing sizes in the UK. We also examined some aspects of outpatient practice.

\section{Methods}

Inpatient diagnoses were examined in one Yorkshire hospital, Pinderfields Hospital, Wakefield, over a period of five years. To assess how representative these data might be, we compared frequencies of diagnoses with those in data sets collected during a BPA/RCPCH study in five Yorkshire hospitals, ${ }^{23}$ and in four South of England hospitals during an unpublished study carried out for the National Casemix Office by the BPA in 1995. In addition, we used published epidemiological reports together with data provided by the Public Health Laboratory Service (PHLS) and Department of Health Hospital Episode Statistics (HES) for England. We modelled the expected frequencies of diagnoses for different sized hospitals based on the Pinderfields Hospital data.

PINDERFIELDS INPATIENT DATA

Diagnoses for each admission are recorded on a database by the medical secretary when typing a discharge letter dictated by the consultant. To account for variations occurring over seasons and years, we used the accumulated diagnoses over five full years from 1 April 1993 to 31 March 1998.

FIVE YORKSHIRE HOSPITALS STUDY

The data describe presenting problems as recorded by the admitting senior house officer (SHO) as well as discharge diagnoses recorded by the consultant. The results have been reported elsewhere. ${ }^{3}$
FOUR SOUTH OF ENGLAND HOSPITALS

This study used a similar data acquisition process to that in the five Yorkshire hospitals study. The SHO on admission and the consultant on discharge completed structured forms including presenting problem and discharge diagnosis. For each of these hospitals, we used a six week data acquisition period including all acute contacts. Results of this study will be reported elsewhere. 
NHS DATA USED

We reviewed recent trends in paediatric workload. ${ }^{4}$

DIAGNOSES

Diagnoses were categorised in the same way for the five Yorkshire and four South of England hospitals, and numbers were pooled and contrasted with national and Pinderfields Hospital data.

EPIDEMIOLOGICAL DATA

As management of acute respiratory and infectious diseases plays a major role in paediatric practice, ${ }^{2}$ we examined admission rates for selected marker conditions. The relevant information was derived from publications, ${ }^{5-10} \mathrm{HES}$ data, and PHLS reports.

ILLNESS SEVERITY IN ACUTE PAEDIATRICS

We assessed level 1 intensive care (high dependency) using predefined measures during a separate study of paediatric intensive care over a three month period in all Yorkshire hospitals in the winter of 1997. Pinderfields Hospital was included in this study. ${ }^{11}$ For the years 1997 and 1998, records of transfers from Pinderfields for paediatric intensive care into the regional centre are available. We compared these data with an analysis by the authors using HES data of results of a study on intensive care needs in the North West region, carried out by the research unit of the RCPCH. ${ }^{12}$

MODELLING

Frequencies of diagnoses were calculated from HES data, and from the previous studies in five hospitals in Yorkshire and four in the South of England. We also used epidemiological information to derive expected frequencies and compared them with the observed frequencies in Pinderfields Hospital. Then, assuming that Pinderfields Hospital was sufficiently representative of district workload, we calculated projected numbers based on diagnoses likely to be encountered in hospitals of differing sizes.

PINDERFIELDS OUTPATIENT DATA

Diagnoses for each attendance are recorded on a database by the medical secretary when typing clinic letters for each new or review outpatient episode. We used data for one year, 1996. The outpatient department of Pinderfields Hospital sees approximately 8000 paediatric attendances annually, of which approximately 1000 are new referrals.

\section{Results}

INPATIENT UTILISATION DATA

Based on NHS statistics data for the year 1993/94, excluding healthy babies, paediatric workload in Pinderfields Hospital ranks 32nd of 190 acute paediatric inpatient units. ${ }^{13}$ Wakefield Health Authority, the main commissioner of local health care, serves a total population of 60000 children aged $0-14$, with a total population of 310000 . As with many hospitals it is not clear what catchment population is served by each of the two hospitals in the health authority. Thus, although we cannot derive an accurate admission rate per thousand population for Pinderfields Hospital, previous studies suggest that the population served is approximately 40000 children, including children from South Leeds. ${ }^{14}$ On this assumption, it would have an admission rate of 63 per 1000 child population per year.

Health service indicators show paediatric utilisation rates for Wakefield Health Authority population as relatively high at 73 per 1000 child population, the national average being 51.5. ${ }^{15}$ This may be related to local differences in clinical practice. For instance, children with minor head injury are admitted under paediatric rather than surgical care. Socioeconomic factors do not provide a sufficient explanation: Wakefield Health Authority rates at 0.79 on the Jarman scale, within the range for health authorities varying from 61.72 (deprived) for East London to -27.62 (advantaged) for East Surrey, with a median of -4.21 . In contrast, Leeds Health Authority lying on the Wakefield boundary has a score of $10.86 .^{16}$

EPIDEMIOLOGICAL DATA

Asthma and gastroenteritis were selected as marker conditions for more common illness. Although paediatric admissions for all causes in England rose by $8.7 \%$ for children aged less than 5 years and $15.7 \%$ for older children between 1989 and 1993, the number of asthma admissions fell slightly over that period (by $0.6 \%$ for those aged under 5 years and $7 \%$ for older children). Nationally, gastroenteritis admissions rose over the same period (tables 1 and 2). Pneumonia admissions also rose slightly over the same period for children under the age of 5 years but fell for older children (table 3). For more serious infections, meningitis and septicaemia, we used a single year, 1993/94, because published data are available. ${ }^{5-10}$ Furthermore, this year was in the post $\mathrm{HiB}$ immunisation era. Serious infections appear to account for approximately $0.5 \%$ of all paediatric admissions (table 4).

\section{DIAGNOSES}

Pinderfields Hospital

Diagnoses for all 12700 admissions over five years in Pinderfields have been used to compare the observed frequency of certain diagnoses with expected frequencies derived from the epidemiological studies and the BPA/ RCPCH data collections (table 5). This shows the extent to which the Pinderfields work can be regarded as typical.

\section{Severity of inpatient cases}

The average percentage of children receiving high dependency care on each shift on the wards was $14.7 \%$ for all Yorkshire hospitals in 1997 and 18\% for Pinderfields. For each of the latest two years, 17 children $(0.6 \%$ of paediatric acute admissions, were transferred from Pinderfields for paediatric intensive care. The NHS paediatric intensive care report estimated an average of 1.2 per thousand child population per year as needing level 2 intensive care. ${ }^{17}$ This would represent $2.4 \%$ of all paediatric admissions based on an average admission rate 
Table 1 Admissions for a common "marker" condition: asthma *

\begin{tabular}{|c|c|c|c|c|c|c|c|}
\hline \multirow[b]{3}{*}{ Year } & \multicolumn{3}{|l|}{ Age 0-4y } & \multicolumn{3}{|c|}{ Age 5-15y } & \multirow{3}{*}{$\begin{array}{l}\text { All child ages } \\
\text { Asthma } \\
\%\end{array}$} \\
\hline & \multirow{2}{*}{$\frac{\text { All causes }}{n}$} & \multicolumn{2}{|l|}{ Asthma } & \multirow{2}{*}{$\begin{array}{l}\text { All } \\
\text { causes }\end{array}$} & \multicolumn{2}{|l|}{ Asthma } & \\
\hline & & $n$ & $\%$ & & $n$ & $\%$ & \\
\hline 1989-90 & 274063 & 32676 & 11.9 & 102352 & 18780 & 18.3 & 13.7 \\
\hline $1990-91$ & 270805 & 32343 & 11.9 & 101963 & 16721 & 16.4 & 13.2 \\
\hline 1991-92 & 278764 & 32177 & 11.5 & 105963 & 18503 & 17.5 & 13.2 \\
\hline $1992-93$ & 281536 & 31917 & 11.3 & 109315 & 16174 & 14.8 & 12.3 \\
\hline 1993-94 & 297927 & 32475 & 10.9 & 118382 & 17456 & 14.7 & 12.0 \\
\hline
\end{tabular}

^From HES admissions data, excluding admissions below age 29 days.

Table 2 Admissions for a common "marker" condition: gastroenteritis *

\begin{tabular}{|c|c|c|c|c|c|c|c|}
\hline \multirow[b]{3}{*}{ Year } & \multicolumn{3}{|l|}{ Age 0-4y } & \multicolumn{3}{|c|}{ Age 5-15 y } & \multirow{3}{*}{$\begin{array}{l}\text { All child ages } \\
\text { Gastroenteritis } \\
\%\end{array}$} \\
\hline & \multirow{2}{*}{$\begin{array}{l}\text { All causes } \\
n\end{array}$} & \multicolumn{2}{|c|}{ Gastroenteritis } & \multirow{2}{*}{$\frac{\text { All causes }}{n}$} & \multicolumn{2}{|c|}{ Gastroenteritis } & \\
\hline & & $n$ & $\%$ & & $n$ & $\%$ & \\
\hline $1989-90$ & 274063 & 20489 & 7.5 & 102352 & 3055 & 3.0 & 6.3 \\
\hline 1990-91 & 270805 & 22654 & 8.4 & 101963 & 3308 & 3.2 & 7.0 \\
\hline $1991-92$ & 278764 & 18883 & 6.8 & 105963 & 2411 & 2.3 & 5.5 \\
\hline 1992-93 & 281536 & 19097 & 6.8 & 109315 & 2779 & 2.5 & 5.6 \\
\hline 1993-94 & 297927 & 21706 & 7.3 & 118382 & 3111 & 2.6 & 6.0 \\
\hline
\end{tabular}

ॠFrom HES admissions data, excluding admissions below age 29 days.

Table 3 Admissions for pneumonia *

\begin{tabular}{|c|c|c|c|c|c|c|c|}
\hline \multirow[b]{3}{*}{ Year } & \multicolumn{3}{|l|}{ Age $0-4 y$} & \multicolumn{3}{|l|}{ Age 5-15y } & \multirow{3}{*}{$\begin{array}{l}\text { All child ages } \\
\text { Pneumonia } \\
\%\end{array}$} \\
\hline & \multirow{2}{*}{$\begin{array}{l}\text { All causes } \\
n\end{array}$} & \multicolumn{2}{|c|}{ Pneumonia } & \multirow{2}{*}{$\begin{array}{l}\text { All causes } \\
n\end{array}$} & \multicolumn{2}{|c|}{ Pneumonia } & \\
\hline & & $n$ & $\%$ & & $n$ & $\%$ & \\
\hline 1989-90 & 274063 & 6427 & 2.3 & 102352 & 2520 & 2.5 & 2.4 \\
\hline 1990-91 & 270805 & 6799 & 2.5 & 101963 & 3372 & 3.3 & 2.7 \\
\hline 1991-92 & 278764 & 7718 & 2.8 & 105963 & 3364 & 3.2 & 2.9 \\
\hline $1992-93$ & 281536 & 7196 & 2.6 & 109315 & 2392 & 2.2 & 2.5 \\
\hline 1993-94 & 297927 & 7685 & 2.6 & 118382 & 2395 & 2.0 & 2.4 \\
\hline
\end{tabular}

${ }^{\star}$ From HES admissions data, excluding admissions below age 29 days.

Table 4 Incidence and notification of pneumococcal and meningococcal septicaemia/meningitis (serious infection) in 1994*

\begin{tabular}{|c|c|c|c|}
\hline Age & $0-4 y$ & $5-14 y$ & $\begin{array}{l}\text { Total cases } \\
0-14 y\end{array}$ \\
\hline Population & 3866980 & 6185528 & \\
\hline $\begin{array}{l}\text { Incidence of pneumococcal bacteraemia at } \\
12.1 / 100000<5 \text { years and at } \\
6.8 / 100000 \geqslant 5 \text { years }\end{array}$ & 467 & 420 & 887 \\
\hline $\begin{array}{l}\text { Incidence of pneumococcal meningitis at } \\
5.5 / 100000<5 \text { years and at } \\
0.8 / 100000 \geqslant 5 \text { years }\end{array}$ & 212 & 49 & 261 \\
\hline Notified meningococcal septicaemia & & & 323 \\
\hline Notified meningococcal meningitis & & & 658 \\
\hline 1994 paediatric admissions all causes & 297927 & 118382 & 416309 \\
\hline $\begin{array}{l}\text { Serious infection as proportion of all } \\
\text { paediatric admissions }\end{array}$ & & & $0.51 \%$ \\
\hline
\end{tabular}

${ }^{\star}$ Based on incidence figures from published reports ${ }^{5-10}$ and PHLS notifications.

of about 50 per thousand. This is a substantially higher proportion than in Pinderfields. However, our analysis of the North West study on intensive care in 1996 yielded a similar figure of $0.4 \%$ of district general hospital (DGH) admissions requiring level 2 or 3 intensive care. There, of 59121 paediatric admissions to 21 DGHs, 257 required level 2 or 3 intensive care. For the remaining children in the population requiring intensive care, the need arose in the regional centre. ${ }^{12}$

\section{Modelling the experience a district hospital can provide}

We calculated the expected frequency of more common illnesses that would occur over a 12 month period for hospitals serving different population sizes (table 6). We based these calculations on frequency of diagnoses at Pinderfields Hospital over a five year period, assuming an admission rate of 63 per 1000 per year. The observed frequencies in Pinderfields Hospital were of a similar order to expected and thus this hospital was taken to be "typical". Upper respiratory infection and viral infection were the most common diagnoses, followed by asthma and gastroenteritis. Table 7 shows calculated expected numbers for less common disorders.

\section{Outpatient practice}

In Pinderfields Hospital in 1996, taken as a representative year, 3002 children attended 7902 times (some children being seen more than once). Table 8 lists diagnoses for $83 \%$ (2485 of the 3002 children). The remaining $17 \%$ of children had a variety of disorders; some of them did not have an established diagnosis but rather had consultations to establish whether or not a problem existed. It is not possible to provide comparative diagnostic data for outpatient clinical workload in other hospitals. The Office of Health Economics reports that in $1994,11 \%$ of children aged $0-4$ years and $10 \%$ aged 5-15 years attended a hospital outpatient department, although this included accident and emergency attendances. ${ }^{18}$ Cooper et al found a similar scale of use at $11 \% \cdot{ }^{19}$ For paediatric clinics alone, $1.5-1.8 \%$ of the population aged up to 15 years were reported to attend for a new appointment and $6.7 \%$ of children attended for review visits. ${ }^{21}$

\section{Discussion}

In an attempt to estimate experience offered for training, we have modelled expected workload in small, medium, and large units. This modelling is based largely from extrapolation of experience in one large district general hospital, Pinderfields Hospital, Wakefield. Other data reviewed suggest that its inpatient activity are representative. The range and frequency of diagnoses are similar in other hospitals studied in the North and South of the country. They also appear consistent with national data. Severity of illness encountered corresponds to that of other hospitals, as indicated by the level of high dependency and transfers for paediatric intensive care. However, the assumptions used for the model require more detailed and structured study to validate the conclusions drawn. The frequency of diagnoses in Pinderfields Hospital is lower for some disorders, which might suggest admission of less ill children, but such an interpretation is not supported by the scale of high dependency or intensive care work observed. Alternatively, this may be a result of failure to identify disorders: for example, in the past two years Kawasaki disease has been identified more often in Pinderfields than before with seven cases treated each year (though this could also result from chance variation). No account has been taken in the modelling for variability in clinical practice. For instance, the manner in which minor head injury care is provided by paediatricians or how ambulatory care is provided. Paediatric admissions for head 
Table 5 Observed frequencies in Pinderfields hospital v expected (see Methods)

\begin{tabular}{|c|c|c|c|}
\hline Diagnosis & $\begin{array}{l}\text { Observed \%: Pinderfields } \\
\text { over five years 1993-98 } \\
n=12700\end{array}$ & $\begin{array}{l}\text { Expected \%: NCO study } \\
1995 \text { and five Yorkshire } \\
\text { hospital studies 1993/94 } \\
n=2193\end{array}$ & $\begin{array}{l}\begin{array}{l}\text { Expected \%: national } \\
\text { data }^{\star}\end{array} \\
n=416309\end{array}$ \\
\hline Upper respiratory tract and viral infection & 19.7 & 18.0 & \\
\hline High dependency care & 18.0 & $14.7 \dagger$ & \\
\hline Asthma & 9.5 & $11.7^{\circ}$ & $12.0-13.7$ \\
\hline Gastroenteritis & 8.7 & 7.1 & $5.5-7.0$ \\
\hline Ingestion & 6.4 & 5.4 & \\
\hline Gastro-oesophageal reflux and failure to thrive & 4.1 & 7.7 & \\
\hline Croup & 3.5 & 4.5 & \\
\hline Pneumonia & 3.5 & 4.9 & $2.4-2.9$ \\
\hline Febrile convulsion & 3.3 & 5.4 & \\
\hline Fits & 2.9 & 4.2 & \\
\hline Urinary infection or renal disorder & 2.6 & 3.3 & \\
\hline Meningitis and septicaemia & 0.9 & 0.4 & 0.5 \\
\hline Intensive care & $0.6 \ddagger$ & & \\
\hline
\end{tabular}

*Year 1993/94 with admissions under 29 days excluded.

†Yorkshire hospitals.

‡Expected $0.4 \%$ (RCPCH North West study).

injury at Pinderfields were $8.6 \%$ of the total compared with $2.5 \%$ in other hospitals studied, reflecting local practices rather than variation in head injury incidence. Other important factors are socioeconomic differences, ethnic population, location, or geographical influences. Certain parts of the country will have a different spectrum of pathology; for example, sickle cell disease would figure more highly in some cities. Furthermore, proximity to tertiary centres will influence the range of disorders managed, and for Pinderfields this has led to a relatively low workload for cystic fibrosis and oncology which are catered for in Leeds.

Our model shows frequency of expected diagnoses in hospitals serving populations of 140000 to 500 000. The smaller district would expect 1800 admissions a year (five a day); this is the minimum size that the Royal College of Paediatrics and Child Health suggests "should be able to provide adequate training experience". ${ }^{1}$ A larger unit, serving a population of 500 000, would admit 6300 children a year (17 a day) and represents the size agreed between RCPCH and the Joint Consultants Committee of the British Medical Association: "the preferred size for an acute general hospital group offering a comprehensive children's service would be a hospital serving a population of $450000-500000 " .{ }^{22}$ The majority of inpatient units currently lie between these two extremes (table 9).

The data presented suggest that numbers of unusual or serious disorders are small in acute general paediatric practice, even when modelled for larger populations. A population of 300000 would offer a range of experience little different from the larger population of 500000 . However, even smaller units would provide generous exposure to common conditions such as gastroenteritis and asthma. For medium size units, the high dependency data suggest that exposure to sick children will be adequate, with good opportunities to manage conditions such as convulsions and pneumonia. Experience with important but less common conditions, such as diabetes and meningitis becomes a matter of chance.

Over recent years hospital admissions have increased but the prevalence of more serious illness has remained static or fallen (for example, haemophilus epiglottitis and meningitis).

Table 6 Frequency of common diagnoses according to hospital size

\begin{tabular}{|c|c|c|c|c|c|}
\hline & & Hospital A & Hospital B & Hospital C & Hospital D \\
\hline Total population & & 143000 & 200000 & 300000 & 500000 \\
\hline Child population- $20 \%$ total & & 28600 & 40000 & 60000 & 100000 \\
\hline Annual admissions - 63/1000 population & & 1801 & 2520 & 3780 & 6300 \\
\hline Diagnosis & $\%$ Pinderfields & \multicolumn{4}{|c|}{$n$ expected per 12 months } \\
\hline Upper respiratory tract and viral infection & 19.7 & 355 & 496 & 745 & 1241 \\
\hline High dependency care ${ }^{\star}$ & 18.0 & 234 & 328 & 491 & 819 \\
\hline Asthma & 9.5 & 171 & 239 & 359 & 599 \\
\hline Gastroenteritis & 8.7 & 157 & 219 & 329 & 548 \\
\hline Ingestion & 6.4 & 115 & 161 & 242 & 403 \\
\hline Bronchiolitis & 4.5 & 81 & 113 & 170 & 284 \\
\hline Gastro-oesophageal reflux and failure to thrive & 4.1 & 74 & 103 & 155 & 258 \\
\hline Croup & 3.5 & 63 & 88 & 132 & 221 \\
\hline Pneumonia & 3.5 & 63 & 88 & 132 & 221 \\
\hline Febrile convulsion & 3.3 & 59 & 83 & 125 & 208 \\
\hline Fits & 2.9 & 52 & 73 & 110 & 183 \\
\hline Urinary infection or renal disorder & 2.6 & 47 & 66 & 98 & 164 \\
\hline Meningitis and septicaemia & 0.9 & 16 & 23 & 34 & 57 \\
\hline Intensive care & 0.6 & 11 & 15 & 23 & 38 \\
\hline Soft tissue infections & 0.7 & 13 & 18 & 26 & 44 \\
\hline Specific infections $\dagger$ & 0.7 & 13 & 18 & 26 & 44 \\
\hline Surgical problems $\ddagger$ & 0.3 & 6 & 9 & 13 & 22 \\
\hline
\end{tabular}

*The high dependency figures may be too high as they are based on winter work.

†Specific infections include chickenpox, malaria - one per year-whooping cough, glandular fever.

$\ddagger$ Surgical problems include appendicitis, intussusseption, inguinal hernia. 
Table 7 Frequency of rarer diagnoses according to hospital size

\begin{tabular}{|c|c|c|c|c|c|}
\hline & & Hospital $A$ & Hospital B & Hospital C & Hospital D \\
\hline Annual admissions-63/1000 & & 1801 & 2520 & 3780 & 6300 \\
\hline Diagnosis & $\begin{array}{l}n \text { Pinderfields over } \\
\text { five years }\end{array}$ & \multicolumn{4}{|c|}{$n$ expected per 12 months } \\
\hline Diabetes & 95 & 13 & 19 & 28 & 47 \\
\hline Henoch-Schönlein & 57 & 8 & 11 & 17 & 28 \\
\hline Meningococcal disease & 45 & 6 & 9 & 13 & 22 \\
\hline Metabolic disease & 32 & 4 & 6 & 10 & 16 \\
\hline Nephrotic/nephritis & 25 & 3 & 5 & 7 & 12 \\
\hline Pyloric stenosis & 19 & 3 & 4 & 6 & 9 \\
\hline Cancer & 17 & 2 & 3 & 5 & 8 \\
\hline Intussusseption & 15 & 2 & 3 & 4 & 7 \\
\hline Acute upper airway obstruction & 12 & 2 & 2 & 4 & 6 \\
\hline Guillain-Barré & 8 & 1 & 2 & 2 & 4 \\
\hline Kawasaki & 6 & 1 & 1 & 2 & 3 \\
\hline Inflammatory bowel & 5 & 1 & 1 & 1 & 2 \\
\hline Idiopathic thrombocytopenic purpura & 5 & 1 & 1 & 1 & 2 \\
\hline Supraventricular tachycardia & 3 & 0.5 & 1 & 1 & 1 \\
\hline
\end{tabular}

Increased utilisation over the years probably reflects concerns by parents and general practitioners to reduce risk to a minimum by admission to hospital. More children are admitted, possibly less ill than before, thereby diluting the presentations of more severe illness. There are also more doctors. Paediatric staffing in the NHS has risen substantially from 870 consultants in 1988 to over double this number in 1999. Middle grade numbers have grown by some 2.5 times over the same period. ${ }^{23}$ For trainees, changes in working hours and protected time taken out of clinical practice have reduced exposure to clinical experience and decision making. This dilution effect may prove a problem in very large units as well as in small ones.

Before deciding whether a unit provides adequate training, it is necessary to consider what a trainee needs to learn and how learning takes place. The RCPCH has defined this in its syllabus and training record, while Delphi style surveys have been used to identify core compe-

Table 8 Diagnosis for 2485 outpatients attending at least once at Pinderfields hospital in one year (1996)

\begin{tabular}{lc}
\hline Diagnosis & Number of children \\
\hline Asthma & 660 \\
Epilepsy & 203 \\
Developmental language or coordination disorders; includes mild to & 187 \\
$\quad$ moderate developmental delay & 183 \\
Failure to thrive & 177 \\
Urinary tract infection & 138 \\
Constipation & 128 \\
Short stature & $121^{\star}$ \\
Severe learning disability & 109 \\
Recurrent abdominal pain & 103 \\
Cerebral palsy & 100 \\
Enuresis & 92 \\
Migraine & 68 \\
Congenital heart disease & 53 \\
Diabetes mellitus & 34 \\
Autism & 29 \\
Innocent cardiac murmur & 24 \\
Puberty disorders & 21 \\
Neurofibromatosis & 15 \\
Glomerulonephritis/nephrotic & 15 \\
Coeliac disease & 13 \\
Congenital hypothyroidism & 11 \\
Neuromuscular disease & 9 \\
Infonic arthritis & 8 \\
Congenital adrenal hyperplasia & 3 \\
Tuberose sclerosis & 3 \\
Diabetes insipidus & 2 \\
Hirschprung's disease & 4 \\
\hline
\end{tabular}

^Includes 27 with Down's syndrome. tencies for SHOs. ${ }^{24}$ Recently appointed consultant paediatricians identified weaknesses of their training as being in research, public health, psychiatry, and management. ${ }^{25}$ The need for a curriculum and regular appraisal was recognised. Clinical experience is only one learning method $^{26}$; other factors include commitment to teaching and support from consultant staff, structure of educational and training opportunities, and implementation of appraisal. Make up of clinical teams and on call rotas may promote or undermine learning, with highly specialised units sometimes having limited outpatient practice or onerous out of hours work. On the other hand experiential learning should continue to have a substantial place. ${ }^{27}$ Trainees also need to develop technical expertise which is likely to require a certain minimum reinforcement by exposure to the techniques concerned. Larger hospitals do not necessarily offer this; for example, paediatricians in small communities in the USA were found to use practical procedures more often than in larger ones. ${ }^{28}$

Required size for training will depend on the training goals: whether these are to provide experience in the treatment of unusual diseases or to offer experience in the process by which identification of such diseases takes place. Too low a workload will offer an infrequent chance of finding more serious illness in a training period of six to 12 months. This might lead to a false impression that the risk of significant disease is so low that it can be discounted and lead to over confidence in managing illness. This risk might also apply to permanent staff in small units although there is no evidence available to support this notion.

Larger units should benefit from an infrastructure of imaging and pathology services used to dealing with the more unusual disorders in children. In very large units the work will necessarily need to be divided into smaller teams and could also lead to a dilution of clinical experience, as may occur in small units, unless arrangements are in place for sharing this. Whatever the size of the unit there will always be clinical conditions that the individual trainee does not experience personally but would be expected to recognise and 
Table 9 Hospital paediatric units by size, based on estimated paediatric admissions

\begin{tabular}{ll}
\hline Annual paediatric admissions & $\begin{array}{l}\text { Number of hospitals in } 1997 \\
\text { (DoH) HES }\end{array}$ \\
\hline Nil & 31 \\
Up to 1800 & 77 \\
$1801-2520$ & 55 \\
$2521-3780$ & 49 \\
$3781-6300$ & 25 \\
$6301-12000$ & 5 \\
\hline
\end{tabular}

manage in future. Thus not all learning can be based on clinical experience.

Therefore we believe it is an over simplification to define adequacy of training simply by unit size. Even small units should be able to offer training in many of the core skills required in both general practice and paediatrics. Furthermore, while larger units, serving a population of 200000 to 300000 , are likely to offer greater experience of less common conditions, these may be encountered only infrequently even when serving the very large population of 500000 proposed in the JCC report. This large population base is not justified from this review alone, especially when the clinical experience is likely to be spread among a greater number of staff. The relatively small number of more complex disorders seen in all general paediatric settings justifies care for unusual disorders in tertiary centres. General paediatric practice can then be focused on developing optimal structured processes of care for the identification of both common and rare disorders. The district hospital can be involved in treating common conditions of varying severity. For less common disorders there is a need for collaboration with or transfer to tertiary centres for specialist care. A period of training in regional centres for each specialist registrar would thus appear to us as justified.

We have focused predominantly on inpatient experience, but many training opportunities can be found in outpatient practice (table 8). The RCPCH proposes that all trainees attend 10 outpatient sessions per six months. ${ }^{29}$ Training needs in community paediatrics have been discussed elsewhere. ${ }^{30}$

The results of our review support the $\mathrm{RCPCH}$ stance over small units. On the other hand the population of 500000 proposed by $\mathrm{RCPCH}$ as being optimal for training is not justified from our review alone. Review of paediatric workload in acute units for 1997/98 shows that only five hospitals of the 214 deal with a paediatric workload equivalent to this population (about 6300 admissions per year; table 9). Even if desirable, closing or amalgamating other units on the scale necessary to achieve this standard would be impractical, and raise issues of access and equity. This is especially important for more deprived populations where acute and chronic morbidity is greater and child and infant mortality higher. ${ }^{31} 32$

We wish to thank the paediatric staff in the Yorkshire hospitals (Grimsby, Harrogate, Huddersfield, Hull, and Leeds) and the southern hospitals (Ipswich, Hastings, Plymouth, and Watford) for their hard work in obtaining the data we used in this paper.

1 British Paediatric Association. Future configuration of paediatric units. London: British Paediatric Association, 1997.

2 Stewart M, Werneke U, MacFaul R, Taylor-Meek J, Smith HE, Smith IJ. Medical and social factors associated with the admission and discharge of acutely ill children. Arch Dis Child 1998; 79:219-24.

3 MacFaul R, Stewart M, Werneke U, Taylor-Meek J, Smith HE, Smith IJ. Parental and professional perception of need for emergency admission to hospital: prospective questionnaire based study. Arch Dis Child 1998;79:213-18.

4 MacFaul R, Werneke U. Trends in hospital utilisation by children and the problem of "healthy babies". Submitted.

5 McIntyre P. Epidemiology and prevention of pneumococcal infections. Curr Opin Pediatr 1997;9:9-13.

6 Djuretic T. Public health laboratory service. Commun Dis Rep 1996;6:R78-80.

7 Laurichesse H, Grimaud O, Waight P, Johnson AP, George RC, Miller E. Pneumococcal bacteremia and meningitis in England and Wales, 1993 to 1995. Commun Dis Public Health 1998;1:22-6.

8 Urwin G, Yuan MF, Hall LMC, Brown K, Efstratiou A, Feldman RA. Pneumococcal meningitis in the North Thames Region UK: epidemiology and molecular analysis of isolates. Epidemiol Infect 1996;117:95-102.

9 Djuretic T, Ryan MJ, Miller E, Fairley CK, Goldblatt D. Dospital admissions in children due to pneumococcal Hospital admissions in children due to pn
pneumonia in England. F Infect 1998;37:54-8.

pneumonia in England. F Infect 1998;37:54-8.
10 Public Health Laboratory Service. Notifications for meningococcal disease. 1990 to 1997 . Personal communication. 1 Fairfield G. Yorkshire paediatric intensive and high dependency study. Leeds: Nuffield Institute, 1997

12 Haines L, Pollock J, Scrivener R. Report on a prospective study of intensive care utilisation in the north west region. London: Research Unit, RCPCH, 1996

13 Statistics Branch, DoH, 1999.

14 Thakker Y, Sheldon TA, Long R, MacFaul R. Paediatric inpatient utilisation in a district general hospital. Arch Dis Child 1994;70:488-92.

15 Department of Health. Health Service Indicators (1993/94 and 1995/6).

16 Public Health Common Dataset. Paediatric Intensive Care. Report by Chief Executive
NHS for Secretary of State. London: NHSE, 1997.

18 Hospital services 37. Office of Health Economics acute inpatient statistics by age group 1980-1995. Compendium of

19 Cooper H, Smaje C, Arber S. Use of health services by children and young people according to ethnicity and social class: secondary analysis of a national survey. BMF 1998;317:1047-51.

$20 \mathrm{Ni}$ Bhrolchain CM. A district survey of paediatric outpatient referrals. Public Health 1992;106:429-36.

21 MacFaul R, Long R. Paediatric outpatient utilisation in a district general hospital. Arch Dis Child 1992;67:1068-72.

22 Joint Consultants Committee. Organisation of acute general hospital services. London: BMA, 1999.

$23 \mathrm{RCPCH}$. The medical workforce in paediatrics and child health 1995-1997. London: RCPCH, 1998.

24 Ilott I, Allen M. Field testing of SHO competencies and specialty specific competencies as pre-requisite for higher speciality specific competencies as pre-requisite for higher speciality
training. Report for $\mathrm{DoH}$ and DfEE. Leeds: University of training. Report

25 Lenton SW, Dison P, Haines LC. BPA survey of recently appointed consultants. Arch Dis Child 1994;71:381-4.

26 Bunch GA, Bahrani J, MacDonald R. Training in the senior house officer grade: how good is it? $\mathrm{Br} f$ Hosp Med 1997;57:565-8.

27 MacFaul R, Werneke U. Risk of presenting problems for illness in district general hospitals. Submitted.

28 Feigin RD, Drutz JE, O’Brian Smith E, Collins CR. Practice variations by populations: training significance. Pediatrics 1996;98:186-90.

$29 \mathrm{RCPCH}$. General professional training guide. London: $\mathrm{RCPCH}, 1999$.

30 British Association for Community Child Health. Syllabus for higher specialist training in community child health. Lor higher specialist training in community child health. 1996.

31 Spencer N, Logan S, Scholey S, Gentle S. Deprivation and bronchiolitis. Arch Dis Child 1996;74:50-2.

32 Cooper H, Arber S, Smaje C. Social class or deprivation. Structural factors and childen's limiting long standing illness in the 1990s. Sociology, health and illness. $7 \mathrm{Med}$ Sociol 1998;3:289-311. 